\title{
Competitive Intelligence Systems in Practice: Investigating Main Issues and Challenges Regarding Acceptance and Usage Behavior
}

\author{
Guechtouli Manelle, PhD \\ IPAG Business School, France. \\ CERGAM, AMU
}

\section{Doi:10.19044/esj.2018.v14n31p15 ～URL:http://dx.doi.org/10.19044/esj.2018.v14n31p15}

\begin{abstract}
Gathering information about competitors and understanding their position is a key issue for any organization. The objective of this paper is to identify the main internal issues when it comes to dealing with Competitive Intelligence Systems (CIS) acceptance and usage behavior. We apply the exploratory research method of grounded theory to analyze a CI System of a large industrial company. At a practical level, our study aims at helping managers understanding the important features related to CIS in the postimplementation stage. At a theoretical level, the aim is to address a gap by explain the several relationships between the different categories of contributing actors and identifying the major problems they face after implementing a CIS. Our study identifies 3 main emergent issues in terms of:1. Internal visibility of the system, 2. Legitimacy and recognition by the management 3. System's technology adoption and use. Results are discussed and managerial implications are addressed.
\end{abstract}

Keywords: Competitive Intelligence issues, Information Management Systems, failure and success factors; post-implementation stage

\section{Introduction:}

Since Porter's five forces, ways of analyzing and understanding the business environment have been widely studied and plethora of concepts appeared: Competitive and Business Intelligence, strategic watch, strategic intelligence, environmental scanning, etc. The abundance of concepts shows the importance of these activities for managers and organizations, and in the same time, shows the lack of theoretical bases in the field. Indeed, Competitive Intelligence systems (CIS) appear to be complicated to define in terms of implementation and management (Søilen, 2017). 
CIS can be seen as 'the art of collecting, processing and storing information to be made available to people at all levels of a firm to help shape its future and protect it against current competitive threats. It should be legal and respect codes of ethics (Salguero, 2017, p. 38). The output of the system is used for supporting both strategic and operational decisions; this output can then be analyzed and converted into knowledge in order to feed up the strategic management system (Shujahat et al, 2017). CIS are basically a way for companies to adapt to the uncertainty and complexity of their continuously changing environment (Wright et al, 2012). Literature has shown a positive correlation between perceived environmental uncertainty and competitive intelligence practices, specifically in terms of intelligence acquisition and strategic use (Alnoukari and Hanano 2017, Yap et al.2013).

Many CIS' implementation failed because of issues in terms of costs, benefits, targets or time limits (Lesca \& Caron-Fasan, 2008). Authors (such as Søilen, 2017 and Calof, 2017) highlight the lack of research studies that could address the specific question of CI issues in organizations with theoretical and practical implications.

Moreover, an important part of the existing literature point to the anticipative role of CIS (Laude, 2016), implementation and tracking phases have been widely studied (Olszak, 2014, Duranti \& De Almeida, 2015) while the post-acceptation part has been less covered (Wang et al. 2014).

Furthermore, literature has shown that the first step to realize IS success is the initial IS acceptance (Bhattacherjee, 2001) and this has been commonly considered (especially through IS models such as TAM, and UTAUT). But, research has been less exploring what happens after this acceptance phase (Wang et al. 2014).

Consequently, our study aims at filling this theoretical gap by addressing the question of achieving IS long term viability and trying to assure its full potential use. In other words, our research will specifically examine the main issues a company must face at the post-implementation stage.

As Kim et al. (2007) has shown that IS usage behaviors are directly influenced by individual beliefs and attitudes rather than external factors, our study will then focus on IS individual perceptions in order to understand what could deter them from participating to the IS at a long term perspective.

Additionally, the aim of this study is practical as one of its major objectives is clearly to provide managers with practical information to help them manage their CIS at the post-implementation stage.

Our approach is based on a grounded theory methodology (Glaser \& Strauss, 1967) as we are analyzing how participants are using the CIS of their company on a post-acceptation stage seeking why and how they are contributing to the system. More precisely we analyze the system by analyzing 
how contributors are providing information, interacting, exchanging and also their personal perceptions of the system.

To be consistent with our chosen methodology, this paper will reserve the traditional literature review until after data collection and analysis. The aim here is to allow data to reveal what is important to our research question rather than applying preconceived theories. So our paper will start by explaining the methodology and concepts for our grounded theory research, then, according to the method, the data analysis, and finally, our results are presented and discussed in the last section of the paper.

\section{The grounded methodology}

When the base of knowledge is limited or suspected of being incomplete, exploratory research appears to be extremely valuable (Johnson \& al., 2010). Grounded theory is described as inductively derived from data representations, contrasting with traditional approaches that test theoretical hypothesis that has been defined ex-ante (Glaser \& Strauss, 1967). Our approach is qualitative as we chose a unique case study (Yin, 1994 ; Eisenhard, 1989), the case is studied in depth, following the recommendations of Miles and Huberman (1994) by analyzing the CI system of a big company that we will call Omega. We will focus on the CIS contributors and will analyze their participation in the system, their interactions with the others, as well as their perception of the system. Our aim is to gather some insightful data and to capture the system's existing dynamics (Hlady Rispal, 2009).

We chose Omega mostly because it is a very large company (more than 15000 employees worldwide and 3 billion euros revenue in 2017). We focused our study on one major site of Omega located in the south of France. Omega evolves through a very competitive and technological market, and has a competitive intelligence team that was clearly identified in the organizational chart. The company is also reconsidering some of its processes and wanted an audit of its CI system in place. In addition, the company agreed in sharing all its information with our research team at one condition: staying anonymous.

We conducted 30 in-depth interviews (see Appendix 1 for respondent's characteristics) with open questions (that lasted from 45 minutes up to 2 hours). We also used secondary data such as organization charts, information about internal processes, and information available through the company's intranet and website.

The first set of interviews were conducted with the CIS staff members (according to the organizational chart), there were 10 employees, 2 full time business analysts ( Full Time Contributors, FTC) and 8 part time business analysts (Part Time Contributors, PTC). The objective was to identify the CI official network and to understand how their members participate, communicate and disseminate information. The aim here is not to be 
exhaustive and precise in defining the structures and relations between participants, this seems complicated for such moving dynamic structures (Angot \& Josserand, 2003).

We used the snowball sampling method (Miles \& Huberman, 1994) by asking every inter-viewed person to lead us to one of her CI (direct) contacts (Patton, 2002). This led us to a second set of interviews where we questioned 11 persons. We will call this category of participants "Casual Contributors" (CC) as they do not officially participate to the CI system but interact casually and unofficially with CI people. This is an indirect and informal participation to the CIS.

This second group led us once again to a 3rd group of contributors (9 actors) that will be called "Potential Contributors, PC" as they do not contribute to the CIS directly but through their exchanges and interactions with the casual contributors.

Finally we reached the theoretical saturation at this point with those 3 categories of actors: 10 official contributors (Full and Part Time contributors), 11 casual contributors and 9 potential contributors.

Our questions covered 3 major themes: 1. system's organization (how do people contribute to the system, what are their information sources, interactions, etc.), 2. Individual perception of the system (opinion, usefulness, ease of use, tools, etc.), and 3. The main issues related to the CIS (problems, information sharing, security, ROI, etc.).

\section{Data analysis}

Our data analysis was based on an emerging thematic coding (Miles \& Huberman, 1994), as categories were revealed gradually. We used the qualitative analysis software Nvivo (11) in order to code and to analyze our data. We organized our analysis and findings according to 2 major aspects: the system's organization (understanding how the system works) and the main issues (that were revealed by the users). Our approach is exploratory and descriptive as we aim to understand the system and its dynamics.

\subsection{CI system's organization}

In terms of organization, the CI system is divided into $3 \mathrm{CI}$ units (along with the 3 business units of the company). There were 5 actors in BU1, 2 actors in BU2 and 1 actor in BU3. As seen before, these are the Part Time Contributors (PTC). They contribute to the CI system officially (CI activities are part of their job about 30 up to $50 \%$ of their tasks are directly related to CI) they also have other functions (strategic marketing department) in the BU.

Those CI units are managed by a corporate team of 2 managers (the corporate market Intelligence Service), called the Full Time Contributors in our study (FTC). These people are in charge of the CI system and drive the 
interactions between the top management and the different CI units. Those interactions were not easy to observe, as the exact contribution of each CI team was not clearly identified. Moreover, participants used several formal but also informal means to exchange information such as mails, phone, informal meetings and discussions, etc.

In addition, our data analysis revealed that PTC and FTC interact with their own network through informal means (essentially by phone), those people are called the Casual Contributors (CC; 11 were identified). The $\mathrm{CC}$ are interacting in an informal way as they are not supposed to provide information and participate officially to the CI system. Those CC also interact with their own network that we will call the Potential Contributors (PC, 9 identified). The PC do not interact with the official CIS members, some of them do not even know that the CIS exists in the company. Figure 1 shows those categories and interactions.

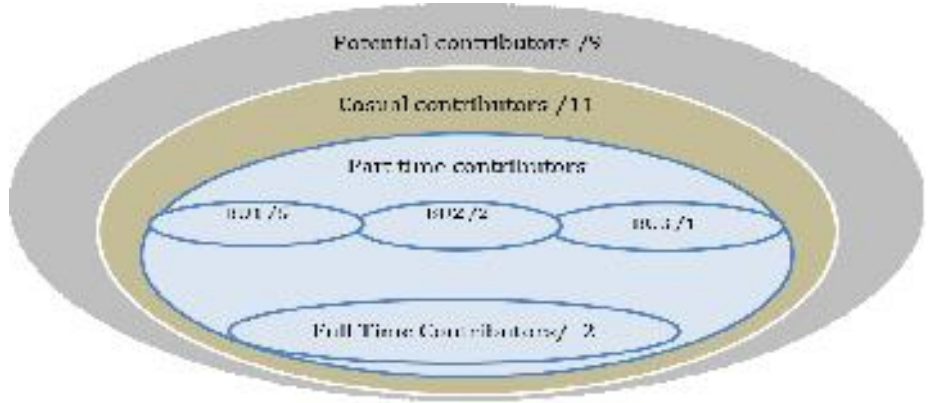

Figure 1: Identified CI categories

Those categories have been identified gradually while analyzing our data in terms of CI activities and interactions. Each category has then been analyzed in terms of the issues it has to face when it comes to using the CIS.

\subsection{CIS main issues}

Our emerging coding has identified 3 major issues. Those issues were seen differently depending on the participants' category (Table 1).

\begin{tabular}{|c|c|c|c|}
\hline Categories & $\begin{array}{l}\text { Lack of } \\
\text { internal } \\
\text { visibility }\end{array}$ & $\begin{array}{c}\text { Lack of } \\
\text { legitimacy } \\
\text { and } \\
\text { recognition }\end{array}$ & $\begin{array}{c}\text { usage of CI } \\
\text { technologies }\end{array}$ \\
\hline CC & $1 / 11$ & 0 & $2 / 11$ \\
\hline PC & $5 / 9$ & 0 & $1 / 9$ \\
\hline PTC & $3 / 7$ & $5 / 7$ & $6 / 7$ \\
\hline FTC & $1 / 3$ & $2 / 3$ & 0 \\
\hline
\end{tabular}

Table1: emerging issues by category. 


\subsubsection{Lack of internal visibility:}

This issue has been mainly identified by the Potential Contributors (PC). Our analysis shows that 7/9 of PC explain that they never heard about the company's CI system. If they do not know the system, they can hardly participate.

'Yes it happens; sometimes I have information about our competitors. I don't think we have any process for that, I generally send it to my manager'. PC3

'I think we used to have someone dealing with this a while ago, he actually was centralizing information about competition, but he left I think about 2 years ago, and now it doesn't exist anymore" PC1.

Potential contributors clearly explained that they were not involved in the CI system. Still, some of them appear to be in the mailing list of the CI newsletter that they actually receive every week. Their answer was that they didn't know who was editing the newsletter and also that they did not really have the time to read all their emails.

'Probably, I must receive this newsletter if you say that I'm on the list... I receive a lot of emails, to be honest, I cannot really read everything' PC2.

'I do receive a lot of emails, I don't have the time to read everything, see everything...we are challenged all the time' PC5.

Our analysis shows also that some Casual Contributors explain that the CI system is quite a mystery for them. Full time contributors are not as present as they should be.

'I often send information to M.Xxxx (a FTC - Ed), I like him, I always try to reply quickly each time he needs me, he's a good analyst, he knows the market. As for the others, I don't know, I can't really tell what they are doing, and I'm not the only one. I think they should communicate about what they do. People would be more open to answer their emails'. CC 7.

This problem of visibility appears also in the Full Time contributors' category but at a different level as some of them explain that employees do not know who is behind the CI system and the way the system works.

'One major issue is to be able to explain exactly what we are doing; many people do not understand our role' FTC1

'Usually people do not know who we are and why we are asking them such things (information about competition - Ed)' PTC7.

\subsubsection{Lack of legitimacy and recognition}

This issue was globally stressed by CI executives as they explained that they do not feel that their work is recognized and valuated by their colleagues. This must be linked with the fact that the CI system and activities are underappreciated. In fact, all the FTC and about 50\% of the PTC explain that their CI activities are not considered as it should be by their colleagues. What's 
interesting is that they do not talk about their managers here but only about their colleagues.

"I think that people do not really understand what we do. Our work is not taken seriously'. PTC1.

'We are the "corporate people", everybody's wondering what's our exact role ...". FTC1.

This lack of legitimacy and recognition appears to be linked with 3 factors: first, a big majority of interviewed people (outside the official CIS) do not seem to understand what CIS means. Most of them explain that they are not concerned; some of them even have negative perception of BI.

'Honestly, I don't know what they are doing upstairs exactly', CC10 (talking about CI executives).

'Oh yes competitive intelligence systems... it's about analyzing competition, someone needs to explain to me what are those systems exactly!' PC6.

This lack of understanding seems to come from a lack of communication as executives did not take the time to explain their CI activities. This is clearly stressed by some full-time contributors.

"People don't know who is sending these emails (talking about competition newsletter - Ed), I do not sign with my own name but as market intelligence service, that sounds better' FTC1.

'As I have two titles, people don't know that I have market intelligence activities, I'm quite discreet about it. I have my network, that's enough for me.' PTC2.

This lack of communication about CI activities is probably linked with the global lack of understanding stressed by many users. This can induce less participation and implication of employees regarding the system's use.

The second factor is linked to the organizational culture of the company and everything that deals with information sharing activities as employees seem not to be open for information sharing. This might be a failing factor as the internal culture of the company does not enhance information sharing $(\mathrm{N}$. Lesca \& Caron-Fasan, 2008, Gretery \& al, 2013).

'(...) Our work is more about making analysis (...) the corporate team does exactly the same thing. We are supposed to work together, to share information. But in reality we don't, we look after our own benefits', PTC5

Thirdly, one other factor that could explain this lack of legitimacy is linked to top management support. In fact, the management does not give away any information about supporting or not the CI activities. This seems to be a significant issue as already stressed in the IS literature (Yeo, 2002, Kapelman \& al, 2006). Our results show that this is also true for CI Systems. 


\subsubsection{Technologies' adoption and use}

Our data analysis shows that globally implemented technologies for CI systems were clearly not matching the needs. This issue is basically identified by part-time contributors as they are feeding and mentoring a system they did not create.

Indeed, the CI technologies are gathering information from different types of employees (such as buyers and price managers all over the world). This information is feeding up the database of part-time contributors. In other words, CI technologies and processes are supposed to support all the CI activities in the company.

At the same time we can notice that full-time contributors do not criticize the CIS, this can be explained by the fact that those people are the ones who have created the system and that they only see positive aspects out of it.

This issue is also linked with another factor: the misunderstanding of what CI activities mean. Indeed, if people do not really understand what CI activities mean, then they will have a hard time understanding the processes and technologies supporting those activities. The lack of implication in the implementation phase of the system could have a negative impact on their effective participation (Gretry \& al, 2013).

Moreover, the implemented technologies do not seem to take into account the user's perspective, it appears to be inconsistent with users' work.

'We already tried several tools in order to support competitive intelligence activities but none of them has really worked 'PTC1

'Now, we got back to a very simple tool (an excel sheet) with the information we need... we just send it to the right person so that they can fill in the blanks. The problem is that people do not really play the game...They do not answer our mails and we have to remind them to do it all the time.' PTC 3.

'The technologies we use are not really suitable. The system is quite heavy and takes a lot of time. It is too complex and probably used at only $2 \%$ of its real potential' $\mathrm{CC} 2$.

We can notice here, that executives are focusing on technical aspects of the system without taking into account users 'needs. It looks like the management is trying to provide technical solutions to what seems to be human problems. Table 2 summarizes the main issues identified in our study for each contributor's category. 


\begin{tabular}{|c|c|c|c|c|c|}
\hline Main issues & Description & FTC & PTC & $\mathrm{CC}$ & $\overline{P C}$ \\
\hline $\begin{array}{l}\text { Lack of internal } \\
\text { visibility }\end{array}$ & $\begin{array}{l}\text { CIS is not clearly } \\
\text { identified within the } \\
\text { company }\end{array}$ & $\mathrm{X}$ & $\mathrm{X}$ & $\mathrm{X}$ & $X$ \\
\hline $\begin{array}{ll}\text { Lack } & \text { of } \\
\text { management } \\
\text { recognition }\end{array}$ & $\begin{array}{l}\text { Lack of (top) management } \\
\text { feedback. }\end{array}$ & $\bar{X}$ & $\mathrm{X}$ & & \\
\hline $\begin{array}{lr}\text { CI } & \text { technologies } \\
\text { 'adoption and use }\end{array}$ & $\begin{array}{l}\text { Difficulties in using } \\
\text { /understanding/adopting } \\
\text { the CI technologies }\end{array}$ & & $\mathrm{X}$ & $\bar{X}$ & $\bar{X}$ \\
\hline $\begin{array}{l}\text { Bad } \\
\text { understanding of } \\
\text { CI concepts and } \\
\text { activities }\end{array}$ & $\begin{array}{l}\text { No definition for CIS. } \\
\text { CIS usefulness is not } \\
\text { clearly identified. }\end{array}$ & & & $\bar{X}$ & $\bar{X}$ \\
\hline $\begin{array}{l}\text { Information } \\
\text { sharing problems }\end{array}$ & $\begin{array}{l}\text { Problems for gathering } \\
\text { information form others. } \\
\text { Internal conflicts }\end{array}$ & $\mathrm{X}$ & $\mathrm{X}$ & & \\
\hline $\begin{array}{l}\text { Top management } \\
\text { support is } \\
\text { missing }\end{array}$ & $\begin{array}{l}\text { Lack of incentives and } \\
\text { enhancement for using the } \\
\text { CIS. }\end{array}$ & & & $\bar{X}$ & $\bar{X}$ \\
\hline
\end{tabular}

Table 2: Identified issues by categories

\section{Discussion}

Our results show that $\mathrm{CI}$ activities are organized as a centralized network (Assens \& Perrin, 2011), this means that those activities are necessarily collective, interactive and open (Calof et al. 2017). The CIS must be managed by a moderator (Kriaa-Medhaffer \& Lesca, 2010). This centralization seems to play an important role in the decision-making process as the moderator of the system is connected to the management in order to support the decision-making processes and the corporate strategy (Guechtouli \& Boudrandi, 2012).

Moreover, we can stress that the link with the managers is different across CIS contributors, only full-time contributors appears to be connected to the corporate strategy. The CI system is supposed to bring support for the decision-making process by providing the good information at the right moment. This appears to be complicated as it is difficult to exactly define the needs in terms of information a priori (Feldman \& March, 1991, Vidal \& al 2005).

We can discuss the results following two major aspects: CI internal visibility/ legitimacy, and CI technologies adoption and use.

\subsection{Internal visibility and legitimacy}

$\mathrm{CI}$ executives are complaining from a lack of visibility and recognition inside the company. In fact those people are not known for their CI activities, and do not really talk about it. It seems complicated for employees to participate if they know nothing about the system. The CIS managers should not neglect the communication (Caron-Fasan \& H. Lesca, 2012) in order to 
explain their activities inside the company and avoid any kind of rejection as this would clearly lead to a lack of participation and implication in the CIS. Indeed, CI information is disperse and difficult to identify (Reix \& Rowe, 2002, Lesca \& Lesca, 2011) so it is complicated to know if someone is contributing to the system or not (one can have information to send one day and no information the other). Moreover, it is not easy to evaluate the contributions in terms of quantity and quality. This supports our first finding: the CI system should be clearly identified in the company (officially) as this will at least give visibility to the system.

The lack of visibility and communication already described contributes to maintain a certain lack of internal recognition because CI contributors do not have the feeling that they are recognized for their work, they do not have any feedback from their colleagues. This leads to a lack of participation and even a lack of consideration and may explain the feeling of lack of legitimacy when it comes to CI activities. This issue is quite similar to the one identified by Trevino \& al. (2014) regarding the factors of internal legitimacy in their study with ethics and compliance officers.

Moreover, the role of the middle management appears to be crucial (Caron-Fasan and lesca, 2012) as it could bring some legitimacy to CI contributors by supporting them officially. At the same time management can use incentives as well in order to enhance CI activities. Even though enhancement and incentives are complicated to implement regarding the nature of CI activities (Guechtouli, 2013).

\subsection{CI technologies adoption and use}

Our study shows incoherence between implemented CI technologies and users' described needs. In fact, full-time contributors have tried to set many internal processes and technologies in order to enhance the CI activities in the company but none of their initiatives worked properly. The problem was that the implemented systems and technologies were aiming at gathering information for either full-time or part-time contributors, but those systems didn't take into account the needs (and also constraints) of employees. This led to the fact that employees did not really understand the importance of contributing to the CI system as this was not directly connected to their work. Literature has shown the importance of explaining and communicating about the system in order to enhance participation and implication of all employees (Gretery \& al, 2013, Caron-Fasan \& H. Lesca, 2012).

\section{Conclusion:}

Our results show that there are still many challenges for CI activities after the implementation phase. First, companies should consolidate their CIS: they must have an identified official structure in order to support interactions 
and also facilitate the identification of CI contributors. The system should be organized as a centralized network. Basically, the system could be more open and collective, it cannot be the matter of a unique person or service as it used to be (Calof et al.2017).

The management is supposed to communicate about $\mathrm{CI}$ activities and CI contributors in order to legitimate the role of the CI contributors and also to enhance employees' global collaboration. Having a formal shape will give the system and contributors strong visibility; this is also clear recognition from the management and could enhance participation as well.

Our findings also suggest relying on existing processes and technologies already implemented in the company in order to avoid change resistance. A lot of employees are already using CI in their work such as sellers, buyers, R\&D engineers, etc. They are already using different processes, so basically, the company will need to rely on existing systems in order to organize and enhance its CI activities. It is very important to take into account the implications linked to organizational changes (Merdinger-Rumpler \& Nobre, 2011) and to the use of ITC (Bou-baker \& Said, 2011).

Our research clearly suggests rethinking globally the function and organization of the CI sys-tem. It is important to keep in mind that the system's organization depends partly on the management and the way executives will perceive and give support to the system. The management also decides on which extend to formalize and shape the CI system.

Finally, our study shows that there is still a room for improving CI systems. In theory, our findings can be seen as a starting point for a larger (quantitative) study in order to confront our results to some different contexts. One suggestion would be to investigate if our results are consistent with other segments, industries or businesses and if the size of the company could have any impact on the CIS management.

In practice, this study could help managers and companies to have a better understanding of the processes and concerns related to CIS and try to improve specifically their CIS management. Our results could also help those managers anticipating the problems of a CIS implementation in order to work gradually and regularly on improving those systems. The major aim here is not only to enhance the global participation in the CIS but also to make sure those systems are used at their full potential in the company.

\section{References:}

1. Alnoukari, M., \& Hanano, A. (2017). Integration of business intelligence with corporate strategic management. Journal of Intelligence Studies In Business, 7(2), 5-16. 
2. Angot J., Josserand E. (2003), Analyse des réseaux sociaux, in Thietart, R.A.(Ed.), Methodes de Recherche en Management, Dunod, Paris, pp.397-421.

3. Boubaker B. and Said K. (2011), Les implications managériales de l'utilisation des TCC dans le secteur hôtelier : le cas du groupe ACCOR, Gestion 2000, Vol. 28 No.6, pp. 95-106.

4. Calof, J., Richards, G. and Santilli, P. (2017). Integration of business intelligence with corporate strategic management. Journal of Intelligence Studies in Business, Vol.7 No.3, pp. 62-73.

5. Caron-Fansan M.-L. \& Lesca, N.(2008), Strategic Scanning Project Failure and Abandonment Factors: Lessons Learned, European Journal of Information Systems, Vol.7 No.4, pp. 371- 386.

6. Caron-Fasan, M.-L. \& Lesca, H. (2012), Projet de mise en place d'une veille anticipative : cas de six organismes du secteur public français, Revue Systèmes d'Information \& Management, Vol. 17 No.2, pp. 81114.

7. Duranti, C. M. \& De Almeida, F. C. (2015), Selection of Online News for Competitive Intelligence: use of Business Domain Ontology for Internet Search Semantic Query Expansion. Global Journal of Computer Science and Technology, Vol.15 No. 6, pp. 10-26.

8. Feldman, M.S. \& March, G.J. (1991), L'information dans les organisations : un signal \& un symbole, in March G.J. (Ed.), Décisions \& organisations, Les éditions d'organisation, Paris, pp. 255-275.

9. Gretry, A., Brandt, C. \& Delcourt, C. (2013), Bilan des pratiques de veille au sein des PME wallonnes. Revue Française du Marketing, No. 241, pp.73 87.

10. Hlady Rispal M. (2009), La conduite d'études de cas encastrées : lorsque le chercheur se livre à un jeu d'assemblage, Revue internationale de psychosociologie, Vol.15 No. 35, pp. 168-187.

11. Guechtouli, M. (2013), Veille stratégique et motivation, Univ Européenne. Grande-Bretagne.

12. Guechtouli , M. \& Boudrandi, S. (2012), Comment Se 'fabrique' La Décision Stratégique: Le Cas D’une Cellule de Veille Stratégique. Recherches En Sciences de Gestion, Vol.1 No.88, pp.35-53.

13. Glaser B. \& Strauss A. (1967), The discovery of Grounded Theory: strategies for qualitative research. Aldine Publishing Company. Howthorne, NY.

14. Johnson, A. J., Egelkraut, T. M. \& Grout, C. (2010), Market intelligence utilization by small food companies: an application of the grounded theory method in exploratory research. Journal of Food Distribution Research, Vol. 41 No.2, pp.58-72. 
15. Kriaa Medhaffer, S.\& Lesca H. (2010), L'animation de la veille stratégique. Cachan : librairie Lavoisier, Paris.

16. Kim, H. W., Chan, H. C. \& Chan, Y. P. (2007), A balanced thinkingfeelings model of in-formation systems continuance. International Journal of Human-Computer Studies, Vol. 65 No.6, pp.511-525.

17. Lesca, H., \& N. Lesca, (2011), Weak Signals for Strategic Intelligence, Anticipation Tool for Managers, Wiley, USA.

18. Laude. H. (2016), Comment détecter des signaux faibles? Un apport des data sciences à la lutte contre la fraude .R2IE, Vol.8 No.1. pp.3853.

19. Merdinger-Rumpler C. \& Nobre T. (2011), Quelles étapes pour la conduite du changement à l'hôpital ?, Gestion 2000, Vol.28 No.3, pp. 51-66.

20. Miles, M.B., \& M.A Huberman, (1994), Data management and analysis methods in Denzin, N.K. and Lincoln, Y.S. (Ed.), Handbook of Qualitative Research, SAGE Publications, Lon-don/New Delhi, pp. 428-444.

21. Reix, R., \& F. Rowe (2002), La recherche en systèmes d'information : de l'histoire au concept in F. Rowe \& Coll. (Ed.), Faire de la recherche en système d'information, 2002, Vuibert- FNEGE. Paris. pp. $1-17$.

22. Salguero, G. C., Resende Jr, P. C., \& Fernández, I. A. (2017). Proposal of an assessment scale in competitive intelligence applied to the tourism sector. Journal of Intelligence Studies in Business, Vol.7 No 2, pp. 38-47.

23. Søilen, K. S. (2017). "Why care about competitive intelligence and market intelligence? The case of Ericsson and the Swedish Cellulose Company' Journal of Intelligence Studies in Business, Vol.7 No.2, pp.27-39.

24. Shujahat, M., Hussain, S., Javed, S., Malik, M. I., Thurasamy, R., \& Ali, J. (2017). Strategic management model with lens of knowledge management and competitive intelligence: A review approach. VINE Journal of Information and Knowledge Management Systems, Vol. 47 No. 1, pp. 55-93.

25. Trevino, L. K., Nieuwenboer N.A, Kreiner G.E \& Bishop D.G (2014), Legitimating the legitimate : a grounded theory study of legitimacy work among ethics and compliance officers. Organizational behavior and human processes, Vol. 123 No.2, pp. 186-205.

26. Vidal, P., Planeix, P., Lacroux, F., Augier, M. \& Lecoeur M (2005), Systèmes d'information organisationnels, Editions Pearson, France.

27. Wang, W., Zhang, Y., Song, B. \& Ren, J., (2014), How to understand post acceptance information system usage behaviors: perspective from 
IS

http://aisel.aisnet.org/cgi/viewcontent.cgi?article=1139\&context=paci s2014

28. Wright, S., Bisson, C., \& Duffy, A. P. (2012). Applying a behavioural and operational diag-nostic typology of competitive intelligence practice: empirical evidence from the SME sector in Turkey. Journal of Strategic Marketing, 20(1), 1933.https://doi.org/10.1080/0965254X.2011.628450

29. Yap, C.S., Abdul Rashid, M.Z. and Amat Sapuan, D. (2013). Perceived environmental un-certainty and competitive intelligence practices, VINE, Vol. 43 No. 4, pp. 462-481.

Appendix 1: Respondents' characteristics.

\begin{tabular}{|c|c|c|c|c|c|}
\hline ID & AGE & Experience in the company & SEX & spot & profile \\
\hline FTC1 & $20-39$ & $5-10$ years & $\mathrm{F}$ & GEMENOS & Full Time Contributor \\
\hline FTC2 & +50 & more than 10 years & $\mathrm{M}$ & GEMENOS & Full Time Contributor \\
\hline PTC1 & +50 & $5-10$ years & $\mathrm{F}$ & La CIOTAT & Part Time Contributor \\
\hline PTC2 & $20-39$ & $1-2$ years & $\mathrm{M}$ & La CIOTAT & Part Time Contributor \\
\hline PTC3 & +50 & more than 10 years & $\mathrm{M}$ & La CIOTAT & Part Time Contributor \\
\hline PTC4 & $20-39$ & $5-10$ years & $\mathrm{M}$ & La CIOTAT & Part Time Contributor \\
\hline PTC5 & +50 & more than 10 years & $\mathrm{F}$ & La CIOTAT & Part Time Contributor \\
\hline PTC6 & $20-39$ & $3-5$ years & $\mathrm{F}$ & La CIOTAT & Part Time Contributor \\
\hline PTC7 & +50 & $5-10$ years & $\bar{M}$ & La CIOTAT & Part Time Contributor \\
\hline PTC8 & +50 & more than 10 years & $\mathrm{M}$ & La CIOTAT & Part Time Contributor \\
\hline $\mathrm{CC} 1$ & $20-39$ & $3-5$ years & F & PARIS & Casual Contributors \\
\hline $\mathrm{CC} 2$ & +50 & more than 10 years & $\mathrm{M}$ & PARIS & Casual Contributors \\
\hline $\mathrm{CC} 3$ & $40-49$ & more than 10 years & $\mathrm{F}$ & PARIS & Casual Contributors \\
\hline $\mathrm{CC} 4$ & $20-39$ & $3-5$ years & $\bar{M}$ & LA CIOTAT & Casual Contributors \\
\hline CC5 & $20-39$ & $3-5$ years & $\bar{F}$ & LA CIOTAT & Casual Contributors \\
\hline CC6 & $40-49$ & more than 10 years & $\mathrm{M}$ & LA CIOTAT & Casual Contributors \\
\hline CC7 & +50 & $5-10$ years & $\mathrm{M}$ & PARIS & Casual Contributors \\
\hline CC8 & $40-49$ & more than 10 years & $\mathrm{F}$ & GENEVA & Casual Contributors \\
\hline CC9 & $20-39$ & $5-10$ years & $\mathrm{M}$ & PARIS & Casual Contributors \\
\hline $\mathrm{CC} 10$ & $40-49$ & +10 ans & $\mathrm{M}$ & PARIS & Casual Contributors \\
\hline $\mathrm{CC} 11$ & $40-49$ & 5 à 10 ans & $\mathrm{F}$ & PARIS & Casual Contributors \\
\hline $\mathrm{PC} 1$ & +50 & $5-10$ years & $\mathrm{F}$ & SHANGAI & Potential Contributor \\
\hline PC2 & $20-39$ & $3-5$ years & M & SINGAPORE & Potential Contributor \\
\hline PC3 & $20-39$ & $3-5$ years & $\mathrm{F}$ & LA CIOTAT & Potential Contributor \\
\hline PC4 & $20-39$ & $5-10$ years & $\mathrm{M}$ & PARIS & Potential Contributor \\
\hline PC5 & $20-39$ & $1-2$ years & $\mathrm{F}$ & PARIS & Potential Contributor \\
\hline PC6 & +50 & more than 10 years & $\mathrm{M}$ & SEOUL & Potential Contributor \\
\hline PC7 & $40-49$ & $5-10$ years & $\mathrm{M}$ & GEMENOS & Potential Contributor \\
\hline PC8 & +50 & $5-10$ years & $\mathrm{M}$ & UK & Potential Contributor \\
\hline PC9 & +50 & more than 10 years & $\bar{F}$ & LA CIOTAT & Potential Contributor \\
\hline
\end{tabular}

